\title{
Design, implementation, and qualification of high-performance time and frequency reference for the MeerKAT telescope (Erratum)
}

\author{
Johan Petrus Burger, ${ }^{\text {a,* Renier Siebrits, }}{ }^{\text {a }}$ \\ Romeo Reginald Gunther Gamatham, ${ }^{a}$ Geomarr van Tonder, \\ Grant Adams, ${ }^{\text {b }}$ Vereesé van Tonder, ${ }^{\text {b }}$ Zwivhuya Ramudzuli, \\ Sarah Buchner, ${ }^{\mathrm{c}}$ Michel Abgrall, ${ }^{\mathrm{d}}$ Pierre Uhrich, ${ }^{\mathrm{d}}$ and Daniele Rovera ${ }^{\mathrm{d}}$ \\ ${ }^{a}$ South African Radio Astronomy Observatory, Time and Frequency Systems Group, \\ Engineering Division, Cape Town, South Africa \\ ${ }^{\mathrm{b}}$ South African Radio Astronomy Observatory, Electronics Group, Engineering Division, \\ Cape Town, South Africa \\ ${ }^{c}$ South African Radio Astronomy Observatory, Commissioning and Science Group, \\ Science Division, Cape Town, South Africa \\ ${ }^{\mathrm{d}}$ LNE-SYRTE, Observatoire de Paris, Université PSL, CNRS, Sorbonne Université, \\ Paris, France
}

[DOI: 10.1117/1.JATIS.8.1.019801]

This article [J. Astron. Telesc. Instrum. Syst. 8(1), 011013 (2022) https://doi.org/10.1117/1 .JATIS.8.1.011013] was originally published with typographical errors in Figs. 3 and 10.

In Fig. 3, in the top blue block, an "approximately equal" sign should have been used instead of an equal sign. Additionally, the symbols \#I and \#J were confused by the authors. Therefore, the text should read $S_{i}{ }_{i} \approx$ (CLOCK- REF) for $\mathrm{i}=1$ to $\mathrm{N}$ instead of $S^{\prime}{ }_{i}=$ (CLOCK \#J- REF) for $\mathrm{i}=1$ to N. Later in the same sentence, the text should read "clock \#J" instead of "clock \#I." The corrected figure is shown here.

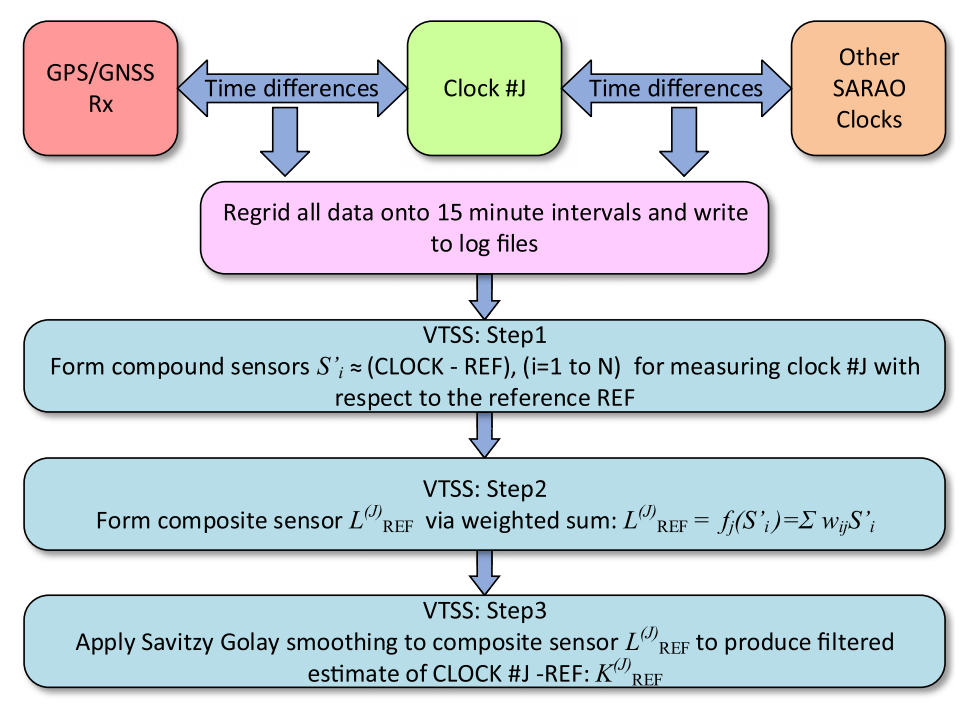

Fig. 3

\footnotetext{
*Address all correspondence to Johan Burger, jburger@sarao.ac.za
} 


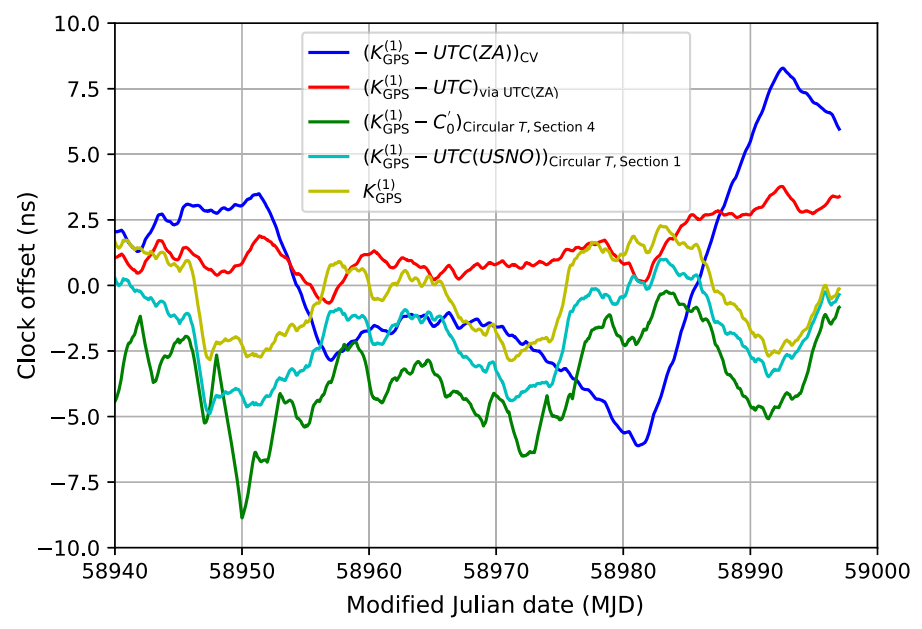

Fig. 10

In Fig. 10, the legend for the green line was incorrectly written as the quantity $\left(K_{\mathrm{GPS}}^{(1)}-C 0\right)_{\text {Circular } T \text {,section } 4}$. The symbol $\mathrm{C} 0$ is, however, $C_{0}^{\prime}$ in the paper's text, and the legend is incompatible with that. Therefore, the figure has been corrected to: $\left(K_{\mathrm{GPS}}^{(1)}-C_{0}^{\prime}\right)_{\text {Circular } T \text {,section 4 }}$. The corrected figure is shown here.

The article was corrected on 21 January 2022. 